\title{
Understanding the Use of Tablet Technology as a Mechanism for Improving Teaching and Learning in the Corvallis School District
}

\author{
Research Report
}

\section{January 6, 2017}

Submitted to:

Corvallis School District

Prepared by:

Nancee Hunter and Martin Storksdieck

Oregon State University

Suggested citation:

Hunter, N. \& Storksdieck, M. (2017). Understanding the Use of Tablet Technology as a Mechanism for Improving Teaching and Learning in the Corvallis School District. Technical Report. Corvallis, OR: Oregon State University. 


\section{Table of Contents}

EXECUTIVE SUMMARY

KEY FINDINGS $\quad 5$

Benefits and Challenges $\quad 6$

Benefits

Challenges

$\begin{array}{lr}\text { INTRODUCTION } & 9\end{array}$

$\begin{array}{ll}\text { BACKGROUND } & 12\end{array}$

RESULTS - TEACHERS 14

$\begin{array}{ll}\text { Teacher Survey } & 14\end{array}$

Teacher Focus Groups $\quad 19$

Elementary Teachers $\quad 20$

Middle School Teachers $\quad 21$

High School Teachers $\quad 22$

$\begin{array}{lr}\text { RESULTS - STUDENTS } & 24\end{array}$

RESULTS - ADMINISTRATORS AND PARENTS 27

$\begin{array}{lr}\text { Administrators } & 27\end{array}$

$\begin{array}{ll}\text { Parents } & 27\end{array}$

$\begin{array}{lr}\text { NEXT STEPS } & 30\end{array}$

$\begin{array}{ll}\text { Theory of Change } & 30\end{array}$

CONCLUSIONS

$\begin{array}{ll}\text { REFERENCES } & 34\end{array}$

APPENDIX A: METHODOLOGY 
APPENDIX B: SUMMARY OF KEY FINDINGS FROM THE CSD TABLETS IN CLASSROOMS RESEARCH

APPENDIX C: PROMISING PRACTICES USING TABLETS AND APPS IN THE CLASSROOM

APPENDIX D: LOGIC MODEL AND THEORY OF CHANGE FOR CSD TABLETS IN SCHOOLS PROGRAM 


\section{Executive Summary}

The Tablets in Classrooms (TIC) program was initiated by the Corvallis School District (CSD) during the 2012-13 school year. TIC provides teachers and students in elementary and middle grades with Apple iPads as new pedagogical tools for teaching and learning. The school district contracted with Oregon State University's Center for Research on Lifelong STEM Learning to explore if, how and when tablets support learning, based on the past three years of experiences from teachers, students, parents, pedagogical and technical support staff and administrators. The goal of the study was to identify key aspects of effective use of tablet devices and to assess the implications of tablet technology use in classrooms. This report is based on a district-wide teacher survey and a number of interviews and focus groups with teachers, students, parents and administrators, in an attempt to capture a variety of perspectives on the affordances and challenges of using tablets in and out of classrooms for the purpose of enhanced instruction and learning.

Overall, there has been evidence to support the use of tablets in classrooms. At the same time, the adoption and integration of tablet devices into schools is not without its challenges.

Teachers were generally positive about the use of tablets, seeing them as essential for 21 st century education. As part of this research, we collected and report numerous examples of how tablets are being used to support learners beyond simple drill and practice games, to support collaborative learning, to provide personalized learning experiences, to enhance student monitoring and assessment, to augment and enhance active learning processes in the classroom, and to provide students with modern productivity tools in support of student work. In addition, teachers report benefits from using tablets for classroom management. There is, however, strong need for increased professional learning opportunities to better familiarize teachers with the pedagogical potential of tablets and similar devices and to provide teachers with effective means to integrate them into classroom practice. Also of note, elementary teachers were more likely to favor shared devices and class sets, whereas middle school teachers preferred 1:1 solutions in which each student is provided an individualized tablet. High school teachers do not have enough experience yet to identify which of these options, or which kind of tablet, is most suitable for their needs.

Students report that iPads are "fun" and easy to use, but they also report that strict policies and content filters limit their ability to download new, useful apps to their tablets. For technical and legal reasons, the school approves which apps will or can be used school wide and manages the download process for apps, which can make the process of adding applications extremely slow. Students also report that teachers might need support to help them troubleshoot downloads or to address other technical challenges, which students feel they could resolve faster on their own. As such, students expressed some frustration with the 'waste of time' spent on technical issues, rather than to use tablets in support of classroom productivity or learning. 
The feedback from parents was mixed (though limited to few focus groups). They identified benefits such as: increased engagement and interest in learning, gains in knowledge and technology skills, more opportunity to make learning relevant and fun, as well as mobility, portability and general ease of use which enables a wider range of learning activities to occur at home. One particular benefit to parents was that their children may not have to carry around heavy school bags any longer. At the same time, parents expressed some anxiety about breakage, theft, loss or misuse of the devices by children, and expressed concern about costs and inconsistencies in what parents are expected to contribute. Parents' biggest concerns related to their children receiving 'too much screen time' and that home-school communication about the program is lacking.

Administrators report that concerted efforts have been made each year to improve the TIC program, based on their own learning and the various experiences reported by users since the program was implemented. Administrators are aware that program cost within the context of limited school funding is of particular concern to some stakeholders, as is the need for more and different technical support to deal with such issues as lack of consistency among different operating systems and interfaces; availability and monitoring of apps; issues of security and data backup; consistent policies; as well as professional development and training; and enhanced communication with key stakeholders.

The report outlines a Theory of Change for the TIC program, which the Corvallis School District can use as a guide for continued long-term planning and effective implementation of tablet technologies (or other digital devices for teaching and learning) in CSD schools. Such planning involves consideration of existing technical infrastructure, networking models, broad stakeholder preparation and on-going engagement as well as processes for capturing progress through continuous feedback. The Theory of Change can also serve as the foundation for assessing the impact of the TIC program on potential key measures of success around enhanced instruction and student outcomes in the disciplines and in technology and information literacy. 


\section{Key Findings}

Overall, teachers who used the tablets perceived them as a 'tool' for enhanced learning. They are used creatively and collaboratively in the classroom, and both teachers and students are still exploring and finding new ways in which tablets can be best utilized. At the same time, it was acknowledged that the tablets placed additional demands on teachers' planning and preparation time. In particular, significant time was dedicated to evaluating and procuring educational apps, determining relevance to the curriculum, and then installing these on individual student devices. The typical apps being utilized are classified as instructive, educational game-based (especially at the elementary grades), content-creation, and 'productivity' apps (e.g., Pages, Notability, Google Classroom). According to teachers, many of the apps have the ability to develop higher order thinking skills and provide creative, individualized opportunities for students to express their understanding of content. The apps also provide opportunities for increased collaboration amongst students.

Teachers believe the tablets support and enhance student learning by enhancing engagement and motivation, improving face-to-face and online collaboration amongst students, personalizing learning and improving learning outcomes. Teachers ascribed these benefits to many factors: the portability of the devices; teachers' ability to easily differentiate instruction and cater to individual learning needs and preferences; the ease with which students can create professional and aesthetic reports, presentations, etc.; how appropriate apps help to scaffold and compensate for students' emerging skills (e.g., text to speech); and the sense of student ownership of their learning. The integration of a range of peripheral technologies (e.g., still and video cameras, voice recorder), and Internet access were also identified as distinguishing features with potential for facilitating learning.

Students and teachers agree that communication has been improved by the use of tablets. Teachers can send out materials and information to students (and parents). Students are able to email teachers with questions or assignments, as well as collaborate with other students on homework and class projects. Teachers involved in focus groups reported that they adopted more innovative, student-centered approaches when using tablets. For example, using a range of multimedia afforded new opportunities for students to demonstrate their learning. Teachers also reported that using tablets resulted in an increase in students sharing digital work; while at the same time providing opportunities for the teacher to provide prompt and ongoing feedback, and to collect assessment data. At the same time, however, there is a disparity between how educators view their use of technology and how students themselves might perceive it. It seems that teachers are not always meeting student expectations about how the technology can and should be used in the classroom. Student feedback suggests that they prefer to bring what they are doing outside of the classroom into their lives at school (e.g., mobile learning, collaboration, and social networking). They see potential in using smartphones, for instance, and they believe the strict policies and filters prevent them from making possible learning connections. In 
addition, the students want to be heard. Students who participated in focus groups reported that they (and other students) may be more technically savvy than their teachers, yet they say their teachers may not be asking for their input on troubleshooting technology.

There are still technical and logistical issues to address. For instance, since tablets are primarily designed as single-user devices, there are challenges associated with school deployment (e.g., Internet connectivity and access). Management time associated with setting up the devices and establishing accounts were identified as barriers to successful use. In addition, teachers (and to some degree, parents) expressed a desire to better understand what types of infrastructure upgrades CSD will be considering in the future, particularly as it relates to connecting tablets to peripheral technologies, such as interactive whiteboards, sensors, probes, projectors, etc. Findings also indicate that there are significant decisions to be made regarding the most time efficient methods of installing and updating apps in accordance with licensing regulations. In addition, the study illuminated the need for future teacher professional learning regarding the use of mobile devices. As tablets are more or less intuitive devices, the emphasis needs to be on pedagogical approaches and task design, rather than on the technical aspects of using the device. The report lists many ideas that were generated by Corvallis School District teachers and staff as to how tablets might be used productively in and out of classrooms to enhance student engagement and student learning.

\section{Benefits and Challenges}

Findings from this study indicate that many of the tablet features offer learning affordances, but also present some significant challenges. Appendix B provides a quick summary of the top pros and cons described by stakeholders. In addition, the primary benefits and challenges associated with tablets in the CSD classrooms are described below.

\section{Benefits}

The greatest benefit of using tablets in the classroom is the access to so much new content and the many helpful apps that are available, which in turn allows for more personalized instruction for every child. More specifically, teachers discussed having easier access to outside information (e.g., various apps and websites, links to homework help, photos and graphics); differentiated content, which levels the playing field for students with special needs; and internal information, such as teacher-created files or websites. In addition, tablets can be used across all subjects and in a variety of creative ways (e.g., making presentations or films, taking notes, playing math games, reading a book of interest, using a calculator, recording a song or listening to music, or simply doing research). Because the tablets allow for a variety of ways to access and present information and more choices and flexibility in how to solve tasks, they make it easier for teachers to organize content and coursework. At the same time, tablets make it easier for students to practice research and technology skills, as well as engage in problem solving tasks; take tests and monitor their own grades; find out what they missed in class, if absent; 
collaborate (e.g., remote sharing); and be more creative (via innovative apps). According to one teacher, students are "going above and beyond the written word to demonstrate their knowledge." A major benefit reported by parents is their children not having to carry around heavy school bags. As it relates to classroom management, teachers are largely happy with the tablets and suggest that it is now easier to share assignments, monitor student progress, and provide prompt feedback (e.g., ability to grade and post on 'Pinnacle'). There is also an increase in opportunities to provide individualized or specialized support and instruction. In addition, the use of tablets cut down on the number of lost materials and 'wasted' paper while limiting time spent making copies.

As a result of these affordances, teachers reported that students are producing better quality research and presentations, are able to be more independent and work at their own level, are more engaged, and are developing technology competencies and learning about Internet safety. There is also more accountability to both teachers and parents. In fact, parents say that their children are proud to show their schoolwork and that they are more engaged with their children's homework. There is also a sense of students being more active learners and less inclined to engage in off-task behaviors (though there is, by no means, a consensus on this). Teachers also suggested that students appear to be able to handle more complex assignments and do more with higher-order skills. In addition, increased motivation in students was reported and a greater willingness to work on specific subject areas. Students also expressed satisfaction with aspects of the tablets, including the ability to receive immediate feedback and a sense of accomplishment and power gained in working with the technology. In the end, tablets appear to provide a means through which a wider range of students can excel.

\section{Challenges}

The greatest challenge reported is the lack of effective infrastructure (e.g., limited connectivity and bandwidth). Filters are perceived to be too restrictive and both teachers and students would like access to more sites. At the same time, parents and teachers are somewhat concerned about trusting the students with these devices, sharing fears about breakages, theft and loss, and about misuse. Concern was expressed around tablets as major sources of distraction in the classroom. Parents shared concerns about the amount of time their children might be using tablets, and in turn, potentially diverting them from time spent with family or friends or being outdoors. Some parents, particularly English language learners, found it difficult to know how to impose boundaries or even know the actual amount of time their children use the tablets each day. Many of these parental concerns may directly relate to lack of communication, and in receiving timely information on the (intended) use of tablets in the classroom. As a result, parents may not necessarily distinguish between issues with digital device use at home from that in classrooms.

Other general concerns relate to the tablets as a distraction for students, potential costs (e.g., damage, upgrades), and loss of important skills (e.g., writing, interpersonal communication). Particularly among teachers, there was a sentiment that not all teachers should be required to 
use these devices. Questions were raised also on whether a 1:1 policy in which each student is issued a personal tablet is appropriate and financially prudent, particularly at the elementary and high school level -- elementary teachers do not seem to use them as often or as long as other grade levels and there is a perception that at the high school level many students already have personal tablets and do not need another one. Research suggests that smartphone use among older students is widespread, while younger students use tablets more often. In fact, according to a recent Pearson study, 75 percent of high school students regularly use a smartphone, whereas only 42 percent of high school students regularly use a tablet at home or school (Pearson, 2015). Nonetheless, not all students have access to this technology, which raises important questions around equity. At the same time, the diversity of operating systems creates technical problems, making consistent use of mobile technology in classrooms based on student's own devices currently very challenging. 


\section{Introduction}

The proliferation of technology and education applications has changed the way educators teach, how students learn, and the way teachers and students communicate. Tablet programs, in particular, are being rolled out in more and more schools every day in hopes of creating interactive learning environments. By the end of 2012, half of the nation's school districts were using some sort of tablet or eReader (MCH Strategic Data, 2012). Technology is far more ubiquitous in education today, with U.S. public schools now providing at least one computer for every five students (Herold, 2016). In a recent study of 3,667 science teachers, nearly all $(98.6 \%)$ of the respondents indicated that they currently use digital media to support science instruction (Reidinger \& Storksdieck, 2016). Consequently, the 2014 National Assessment of Educational Progress (NAEP) found that half of students in 8th grade reported using a computer or other digital technology to create, edit, or organize digital media at least once a month in school and $41 \%$ did so outside of school ${ }^{1}$.

Since 2012, the Corvallis School District (CSD) spent more than \$1 million on iPads and upgrades to school wireless networks; distributed tablet computers to every student at Mountain View Elementary School, Linus Pauling and Cheldelin middle schools; and announced plans to provide every student in the district with an iPad and to replace the iPads every three years, with an estimated cost of approximately $\$ 1.2$ million annually. Early research shows that tablets in classrooms have the potential to significantly enhance learning, allowing teachers to function in ways they have not been able to previously. For example, teachers now have the ability to provide instant feedback and personalize instruction for their students. They are also able to track student learning progress. And, they have access to a wide range of applications, which can serve a variety of purposes (e.g., note-taking, reading, research, developing presentations, or learning games). Using tablets and the Internet to transform the classroom can not only make learning more fun and engaging for students, but can also give teachers a way to see exactly how well each child is learning and customize lessons accordingly. With worksheets and a whiteboard, a differentiated classroom is difficult to accomplish; with tablets--and a teacher who understands how to use them--it is much easier. In addition to differentiated instruction, potential outcomes of learning with tablets include: higher motivation and engagement for students, greater and equal access to information, utilization of pedagogically-sound apps and other tools that can enhance learning; and critical technological literacy and research skills in an evergrowing information age.

However, providing students (or teachers) with tablets is only the first step. In order for digital technology to live up to it's potential for enhancing or changing teaching and learning, it needs to be embedded into an overall context of ongoing pedagogical and technological support (National Research Council, 2011).

\footnotetext{
${ }^{1}$ https://www.nationsreportcard.gov/tel_2014/\#results/infocommtech 
For the past year, the Corvallis School District (CSD) has been working with Oregon State University researchers from the Center for Research on Lifelong STEM Learning (CRL) to help the district study how it can improve the implementation of the program. More specifically, the study aims to give voice to all stakeholders by tapping into the local knowledge accumulated over the length of the program and to harvest ideas for how to use the tablets effectively in the classroom in order to accomplish a variety of goals and to better address challenges.

This formative study focused on aspects of use and usage, with the purpose of deriving recommendations for procedural, organizational and technical improvements. The following is a detailed listing of questions that guided this research.

\section{For teachers:}

a. Instructional change: What types of instructional changes have occurred with tablets? Who has made these changes and why? What do these changes look like? How do individual changes potentially add up to new instructional strategies in general? What do these new instructional strategies look like? How do these instructional changes relate to other uses of digital technology?

b. Training needs: What is the minimal level of initial training that most faculty require to productively implement the tablets in their classroom? Who might be best positioned to provide initial training? What are potentially effective ways to provide this training?

c. Support: What are the technical and pedagogical support structures and specific support activities needed to sustain ongoing (rather than sporadic and episodic) effective use of tablets as teaching and learning tools? Who should provide this support? To what degree can ongoing support be thought of as ongoing peer learning? What are technical or procedural barriers for effective use of tablets in and out of the classrooms?

d. Communication: What knowledge and skills are required in order to continue use and experimentation with tablets as instructional technology? What ongoing feedback do teachers and students need in order to optimize learning processes supported by tablets? What level of sharing with peers, experts and supervisors is required to turn a "best-use-scenario" into a common practice within a "learning community"?

\section{For parents/community/school board:}

e. Goals: What do these groups know about the goals of the program? How can these goals be best communicated to them?

f. Benefits: What benefits, if achieved, would convince stakeholders that the use of tablets as learning and teaching tools is warranted? What benefits and goals do these stakeholders pursue?

g. Making the case: What would be convincing evidence that embedding technology (in the form of tablets) into the school experience benefits student learning without creating unintended harmful effects? What are concerns about using tablets as learning and teaching tools?

\section{For students}


h. Disciplinary learning: Do tablets help in learning disciplinary concepts? If so, why or in what ways?

i. Engagement: How does tablet use influence student engagement with learning? Can we monitor student engagement through the tablets?

j. $21^{\text {st }}$ Century skills: Tablet use might help students practice information technology as a means to learning itself. Does this occur? Are there other so-called $21^{\text {st }}$ Century Skills that are being practiced by students when they engage with tablets as instruments for learning?

k. Technological literacy: Technological literacy can be understood as a precursor for information literacy, which is the broader concept that includes finding and selecting relevant and valid information for specific decision-making. Technological literacy encompasses familiarity, comfort and facility with the technology that supports information literacy. Do students develop familiarity and comfort with this particular kind of information technology (tablets)? Do familiarity, comfort and facility transfer to other forms of digital technology? For instance, does it lead to more sophisticated use of online resources for information gathering and processing?

\section{Around integration:}

I. Integrating tablets into classroom management systems: Is it possible to integrate the tablet use within a structured online classroom management system (as is now widespread in higher education)? Under what circumstances can such a system provide critical information to students and teachers that will help optimize individual and group learning processes? 


\section{Background}

The Corvallis School District introduced about 4,000 tablet computers into classrooms with the intent to

(a) provide teachers and students with current technology for information accessing and processing;

(b) spark improvements to teaching and learning in the disciplines through opportunities afforded by this technology; and

(c) create exposure, familiarity and facility with using modern information technology by utilizing this technology as part of classroom instruction and the extension of learning throughout the day.

The school district introduced these tablets about three years ago and provided limited guidance so that use and usage could occur as emergent practices by local teachers, students and caregivers; particularly teachers were encouraged to experiment with tablets as instructional technology. During this time the school district gathered valuable initial experiences. Excellent examples of early adopters who are utilizing tablets in innovative and productive ways to enrich and improve learning opportunities for students show, in principle, the potential of tablets; however, the broad introduction of this technology also revealed invariable technical, administrative and pedagogical challenges that require close attention in order to ensure that this particular investment into learning technology benefits all students.

The school district retained the services of the technology consultancy BrightBytes which accompanied the introduction of tablets into district classrooms with a baseline survey of teachers and parents. The survey provided insights into a variety of critical issues, from computer use and Internet access by teachers and students at home and in schools to teacher attitudes towards digital technology as instructional tools. A series of reports in late 2014 by BrightBytes documented the current status quo, and revealed that attitudes towards using digital technology in classrooms was positive, even as gaps still existed in widespread readiness. The analysis allowed the school district to address critical issues in the technology infrastructure.

With the benefit of two to three years of on-the-ground practical experiences, the CSD decided it was now time to systematize what has been learned from this initial phase of experimentation, and - using these lessons learned - to optimize the utilization of tablets for learning in and out of classrooms.

The introduction of new technologies in any setting requires careful support, but also ongoing monitoring of adoption, adaptation and usage in order to help teachers and students optimize their use, and to document and - where and when appropriate - measure outcomes and impacts of the new technology on teaching and learning. To this end, the CSD and the Center 
for Research on Lifelong STEM Learning collaborated on a flexible and responsive research and evaluation process that would accompany the current "tablet program" of the district.

The focus of this second phase of research, following on the footsteps of baseline and background data provided by BrightBytes, consisted of a systematic review of the potential that tablets provide, derived from the perspective of key stakeholder groups: students, teachers, caregivers/parents, and administrators. The purpose of the study was formative in nature; exploring and systematically and objectively recording the lessons learned from past experimentation in order to provide user feedback for the next phase of implementing tablets as digital learning technology in the CSD. This next phase will consist of direct technical and pedagogical support for productive and effective utilization of tablets in every classroom, based on experiences in Corvallis schools and supplemented with evidence for promising or best practices from research and evaluation elsewhere. The next phase also consists of an expansion of the current program into High Schools.

Following this study and the improvements and enhancements to the current and future tablet program that will likely result, a quantitatively-based summative or impact evaluation of the program will be merited, focused on critical student learning outcomes that are associated and expected from using tablets as means of instruction and learning. We would expect that a period of about three years of optimized usage be required before a summative evaluation would provide a fair and objective assessment of the program's impact. 


\section{RESULTS - Teachers}

\section{Teacher Survey}

The CRL team constructed a short questionnaire around the use of tablets; it was administered to all teachers in the CSD. Figure 1 shows the total number of teachers in the CSD for the 20152016 school year, broken down by grade range (elementary, middle, and high). During this time, there were a total of 382 teachers in the district. Of this total, 196 teachers completed the survey for a response rate of $51 \%$. The survey used two questionnaires: one for elementary and middle school teachers (where tablets have already been introduced), and a separate one for high school teachers (where tablets will be introduced this year). At the elementary school level, eleven percent of the total respondents have never used tablets in a classroom and only one percent from middle school never did. Thirty-three percent of the high school teachers are not currently using digital devices in the classroom (see Figure 2).

Figure 1. 2015-2016 School Year Teacher Breakdown (Total Teachers $=382$ )

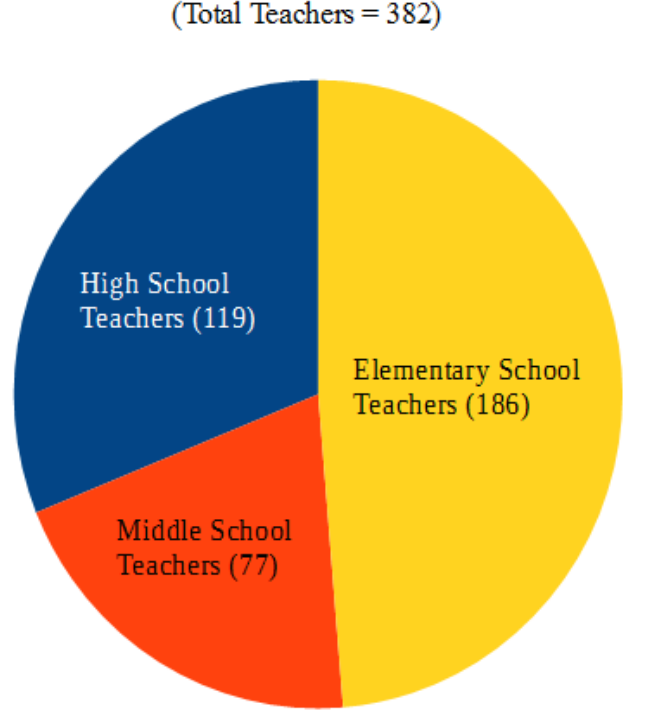

Figure 2. Total Respondents (by Grade Level) Who Have Never Used Tablets

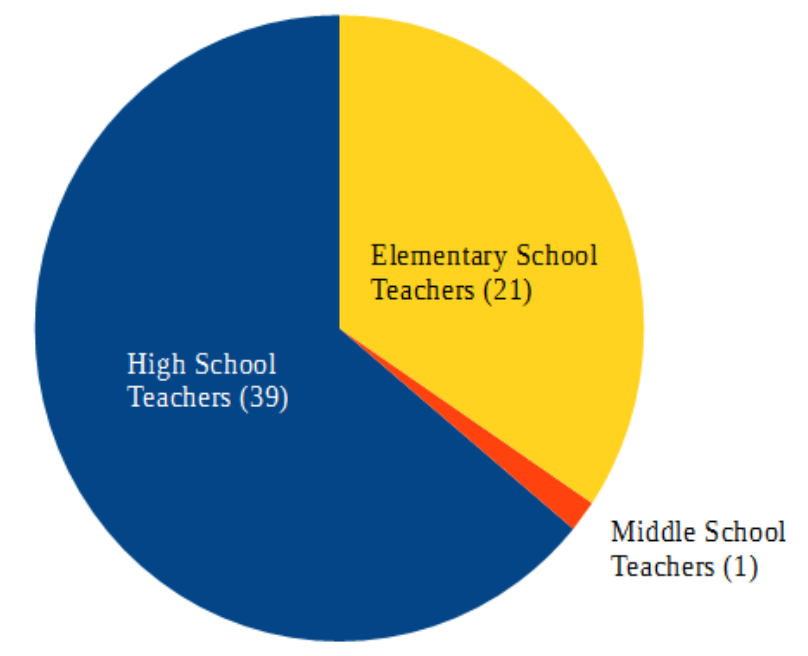

The goal of survey was three-fold: (1) to inform all teachers of the study, (2) to provide all teachers an opportunity to give feedback, and (3) harvest ideas for tablet-based pedagogy. More specifically, the survey asked teachers to rate their own use of tablets, their attitudes towards tablet use, and their experiences with the current program.

The results of the teacher survey reveal that at the elementary and middle school level (those who have had access to the tablets for at least one year) the primary issue that prevented the relatively few teachers from using the tablets was lack of access to tablets themselves.

Secondarily, not being comfortable with the technology, lack of time, unfamiliarity with the technology, lack of interest, and technical issues had relatively equal weight. 
Sixty-seven percent of K-12 teachers believe that the tablets are useful to the students they teach. And, when asked to describe how the tablets have been most useful to students, the top responses from teachers are as follows:

1. Quick and more access to:

- information (e.g., various apps and websites, links to homework help, photos)

- teacher files, websites, etc.

- technology (e.g., Internet) that might not be available outside school environment

- differentiated content

2. Students are:

- producing better quality research and presentations

- able to receive immediate feedback

- able to be more independently and work at their own level

- learning about Internet safety (digital citizenship)

- more engaged

3. Easier for students to:

- research data

- take tests

- monitor their own grades

- find out what they missed in class

- be more creative

- $\quad$ practice research and technology skills, as well as problem solving

4. New opportunities for teacher to:

- grade and post on 'Pinnacle'

- provide individualized/specialized support and instruction

- create quick responses and assessments

There was significant concern around the difficulty of the tablets becoming distractions if and when they are not used for the correct reasons. In addition, forty-five percent of the respondents described major challenges that they have encountered when using tablets in their classroom. Of those responses the majority had to deal with the following:

1. Poor internet connection

2. Technology glitches (e.g., apps not downloading properly, student work and data being lost during submissions, battery life, blocked sites, frequent updates/pop-ups)

3. Students not having their devices available (forgot to bring to school that day) or not charged for classroom use or tablets generally not working for other reasons

4. Classroom management issues when some students are not using the tablets appropriately (e.g., distracted by other apps or websites, some students have difficulty staying off the device).

Other issues include: inability to stream things from the students' iPads; no interface from iPad to projector; the tablets do not support specific software or other technologies (e.g., Adobe, Vernier wireless probes); very few resources available in Spanish; hard to set up consistent, 
reliable systems; often takes time to get everyone to get onto sites or randomly knocks them off; the process for getting new apps on iPads has been difficult; lack of time to create appropriate instruction; access issues when tablets are shared between classes; access to only a handful of tablets in a large class; students not being able to successfully access the internet at home; lack of professional development and training for teachers.

Roughly $81 \%$ of educators surveyed rated the digital devices that they are currently using in their classrooms as very useful (42\%) or somewhat useful (39\%). And, when it came to which technological devices teachers would most like to have access to in their classroom, they tended to favor laptops, notebooks, or Chromebooks, with tablets coming in as a close second; smartphones were not favored by teachers as digital pedagogical devices.

While the majority of educators (69\%) expressed overall satisfaction toward the use of tablets in the classroom, $19 \%$ were unsatisfied and $12 \%$ were neither satisfied nor unsatisfied. Figure 3 summarizes how Corvallis School District teachers rated the overall usefulness of tablets in their classrooms. More than half saw them as "very useful" and another third saw them as "slightly useful". Fewer than 1 in 11 teachers saw them as "slightly" or "very useless". In fact, hardly any teachers considered them "very useless". When asked what they see as major benefits of using digital technology in the classroom, student access rose to the top of the list. On the other hand, reliable and safe access to the Internet, need for technical support, time management, and potential for distractions were considered major drawbacks or challenges of using digital technology in the classroom. 
Figure 3. Total Percent of Teachers Rating Overall U sefulness of Tablets in Classroom

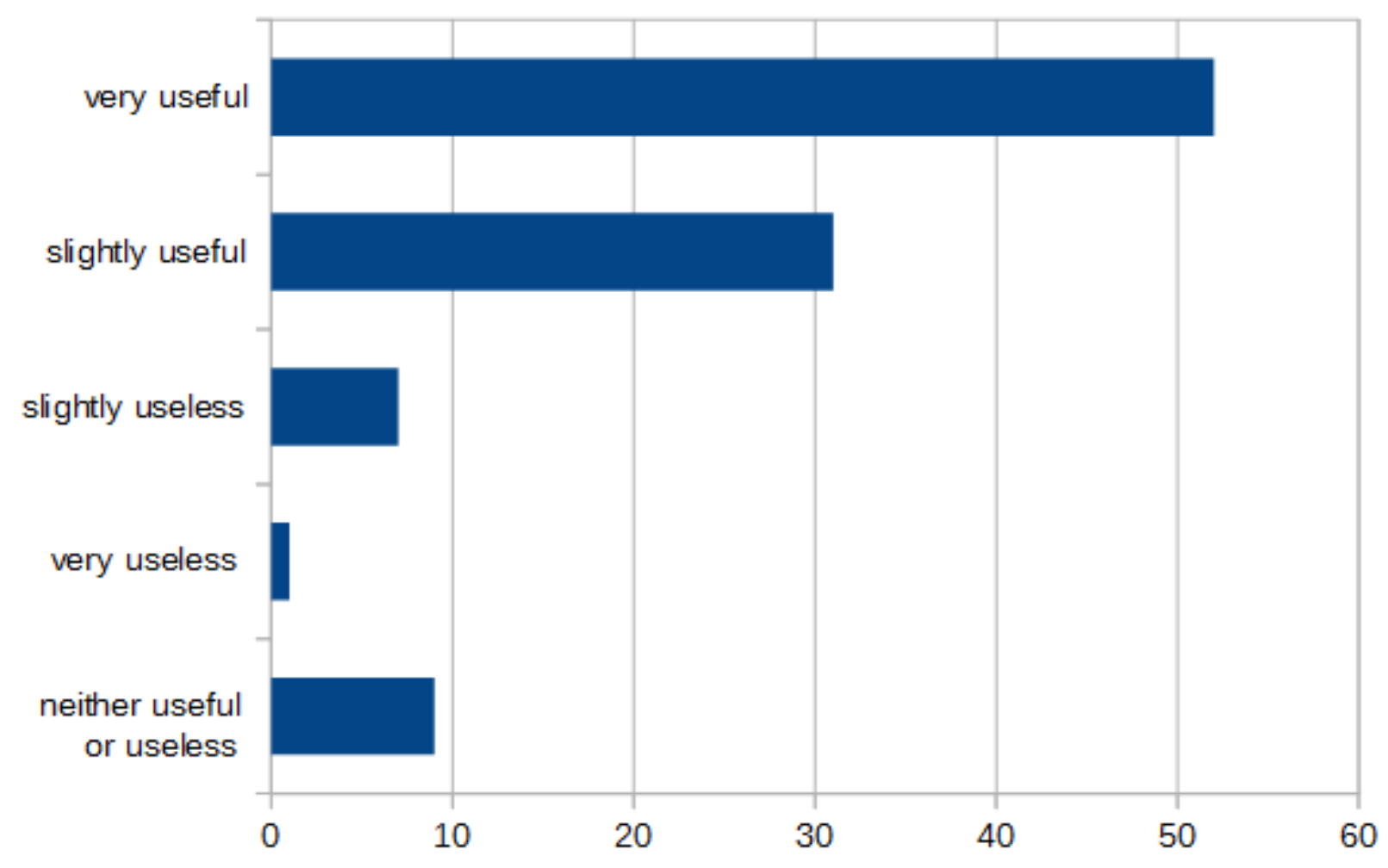

While many teachers expressed positive attitudes toward the use of technology in the classroom, others are resistant to this change. Almost a fifth of responding teachers (17\%) stated that implementing new technology provides little benefit for students or teachers. Nonetheless, most teachers described a happy medium with technology (i.e., it is useful in some situations, but a distraction in others). Appendix B provides a list of the top pros and cons that surround the CSD technology in the classroom debate.

Not surprisingly with a project this large, some difficulties were experienced. Some teachers complained that they could not access the Internet in the classroom via the devices. Teachers did not feel that they received adequate training. Some students bypassed security measures and accessed prohibited websites. And, the program drew opposition from parents, with some saying school officials had not justified the need for the devices, while others worried about the additional time children spend staring at a screen. Overall, however, teachers were generally positive about tablet use in their classrooms. The ability to communicate with students within school and outside was an important factor in engaging students in learning; in addition, instant access to student work and teacher feedback allowed teachers to better serve struggling students. Many teachers reported higher levels of motivation and engagement and students' working in new and exciting ways, while at the same time learning more collaboratively. Teachers also commented on how adept students are at finding and sharing content and appropriate apps, and how skilled they were becoming in this process. 
The following direct quotes from teacher survey respondents help to better illustrate and summarize teacher opinions about the program:

$>$ Technical Support

- "The District is good at spending on hardware, but not support, including technical support and infrastructure. If we all log on at same time, the server can't handle it, for instance. When there is a problem and people helpers are part-time and not nearby, it is really frustrating. Filters continue to be an issue and we can't access new sites because they're blocked - this is not always the case on teacher computers, but it is for students, so I think everything is or will be fine and yet the kids can't get on.... If I have to complete a work order and wait for a really slow response, that is no good. When we are teaching, the need for support is immediate. And, what can I say, textbooks always work."

$>$ Differentiated Learning

- "It offers more and better practice because if someone needed differentiated learning before, the kids would be standing in line and the teacher would be handing out materials and now kids can go directly to their tablets and find the level they need and they are corrected as they go through the content."

- "The ability to provide differentiated instruction, feedback, and engagement is evident in the integration of technology. This definitely shows in the data and is progress towards getting our students graduated."

- "The whole purpose and benefits of the program is to promote a shift in personalized learning."

\section{Access}

- 'Tablets are a novelty in students' hands with so many attractive nuisances. It can actually be disengaging with kids watching football games or playing video games."

- "For students with disabilities, it is a common device that everyone has access to including those who struggle to read and it is not different looking or unique so there is no identifier that a student is special needs. Kids with autism benefit from social stories which help them to understand how to go through various interactions with others (e.g., what they are allowed to do or not do and the consequences). This is done using pictures and videos. The additional access means that all kids are integrated and included." 
- "My child has struggled with learning and can now approach things in the same manner as others to navigate the world and in turn, she has a higher level of independence."

- "The fact that it opens a door and provides access to so many things may not be a positive outcome. We may be giving students more distractions."

$>$ Sensory Overload

- "There is a lot of brain research about the effects on attention span and the benefits of silence, boredom, and daydreaming, which allow for innovation and creativity. The latest and greatest shiny and new thing doesn't fix everything. Walking in the forest provides quiet and may have as much value as the Internet and always looking things up. I have philosophical and pedagogical differences. I think we can saturate our kids. These digital devices are simply tools, in the same way chalk and whiteboards are or have been. They are not about learning. Just being plugged in and able to provide a quick response is not the best approach to learning. I think down time is okay and that we should not overwhelm students with sensory input."

$>$ Collaboration

- "When these devices are utilized well, students can work more collaboratively with other people and there are a multitude of delivery mechanisms."

$>$ General Benefits

- 'We've seen 56\% urgent intervention reduced to $35 \%$ in 3 months. There are 805 students at or above grade level today, yet only 445 were at the beginning of the school year. This model allows us to monitor progress and see how students need extra support. Top level of needs have been reduced drastically and I know this implementation is a huge factor."

- "There are some great benefits to English Language Learners (ELL); we are not leveraging this yet, but it is coming quickly. I believe there are around 50 different languages spoken in our schools."

$>$ One-to-one

- "The program needs to be seamless, streamlined, and level the playing field by making devices available only to families who need or want one. I guess that approximately $60 \%$ of my students would already have a tablet and therefore not need another one."

\section{Teacher Focus Groups}

The primary goal of the teacher focus groups was to glean promising practices and pedagogical ideas for incorporating tablets in the classroom, based on teacher experiences. Appendix C - 
'Promising Practices Using Tablets and Apps in the Classroom' consists of a comprehensive list of these responses. Hence, we provide only general impressions from each of the teacher focus groups below.

\section{Elementary Teachers}

Elementary teachers were more likely to favor shared devices and class sets, as opposed to 1:1 devices. Typical uses at the elementary level are to read a personalized selection of books, play learning games that reinforce the curriculum, and create projects that demonstrate what students learned. The greatest perceived benefit is that the tablets allow teachers to personalize instruction for every child. If a student is struggling, the iPad can offer repetition (through games, targeted reading, or apps) and if another needs to move faster, they can be directed to a faster-paced game or app.

Countering the common parent complaint about too much screen time, one teacher pointed out that most parents equate screen time with passively watching television, yet the tablets are interactive learning tools and customized books, and that the kids do not use them any more than they use other learning tools (e.g., toys, pencils, paper and white boards). When asked for some measurable examples of success, one teacher said that she observed a demonstrable change in that nearly all of her first grade students were reading above grade level - and that this was a first in her long teaching career. The teacher went on to say that nothing else changed so it could only be attributed to the new technology.

Teachers also indicated that students, even at the elementary school level, are able to acquire an impressive level of skills with a broad range of software and that the students are acquiring a basic understanding of how various computer tools behave. In turn, they are building a confidence around learning to use new tools and software applications. Another teacher suggested that elementary school is probably the best place to expand the creativity of students and that tablets help kids become more creative through various applications designed for drawing, sketching and painting. There are also numerous apps that allow kids to create stories and videos, or to boost creativity through games. There was a general agreement that kids need to be technology literate, regardless of age.

An elementary school principal, in an interview, echoed what many of the teachers felt when saying, "They [the students] are actively participating in every single part of the lesson. They're excited, they like it, and that's reaffirming for the teacher and the student." A fifthgrade teacher said that, "...students have been learning so much by having the iPads, including how the technology works and learning more information about various topics."

There are many benefits to allowing students in elementary school to utilize tablets in the classroom, most notably are:

- Differentiated Instruction: Students can each receive individual math problems to solve, e-books to read, or websites/topics to research; both content delivery and 
students' assignments can be varied based on students' interests and readiness levels. This can all be done discreetly as well, so no student knows that others are working on easier or more difficult tasks.

- Presentation of Schoolwork: Like older learners, elementary students need to feel that they have valuable things to say. Tablets allow students more options for creating and sharing their work, whether it is through writing, presentations, audio, or video files.

- Developing Digital Citizens: Elementary students become comfortable with technology.

- Increased Student Motivation: Students are frequently more motivated to learn.

Overall, CSD teachers do not believe that elementary school students are too young to benefit from using tablets. However, there is recognition that care must be taken to ensure that the benefits of new technologies are maximized for young students without taking away traditional learning tools and experiences, like physical books, manipulatives (e.g., learning blocks or dominoes, money, string, rulers, measuring cups, or thermometers), and opportunities for physical movement. Ultimately, the TIC initiative is seen as being about students having ubiquitous access to technology when it is beneficial. Teachers recognize that the program does not suggest that students will use technology all day, or every day as part of their classroom experience.

\section{Middle School Teachers}

Middle school teachers discussed the efficiency of message boards such as classroom websites, Corkulous, and Showbie as drop-points for assignments and resources. By placing electronic versions of assignments online, teachers felt that they cut down on the number of lost instructions and "wasted paper" while limiting time spent making copies and conducting related administrative tasks. Going "paperless" also means that teachers have less physical paperwork to monitor. Using apps such as Socrative or Duolingo, quizzes and in-class activities can be administered and stored for grading online. With 24/7 electronic turn-in systems like Showbie, teachers felt that students have more accountability both to teachers and parents. Students can turn in assignments at their convenience, while parents have easy access to view students' grades and assignment records. This, teachers report, allows for more frequent dialogue between students, teachers, and parents about student's progress in the classroom. In terms of accessibility, teachers said that the ability to quickly enlarge text, "write" through typing, utilize dictation, annotate images, and have text read aloud has been beneficial to all students, regardless of development levels. These features proved to be especially important for students with physical and motor impairments.

Teachers strongly expressed the importance of developing technological competency among their students and emphasized the innovative freedoms that tablets provide in terms of production of schoolwork. Applications such as Notability, iMovie, Educreations, Garage Band, Keynote, and PowerPoint enable students to "go above and beyond" the written word in terms of demonstrating their knowledge, while teachers have found meaningful ways to 
share feedback through the analysis and annotation of video performances (e.g., for music assignments and speeches), voice memos, and written notations.

The biggest challenge reported by middle school teachers relates to infrastructure and connectivity. Teachers suggested that content filters are too restrictive and they would like access to more sites. One teacher suggested that filtering websites does the next generation of digital citizens a disservice, because students need to learn how to evaluate the accuracy of information from all types of sources. Another teacher says: "As an educator, I have a responsibility to produce media-literate members of society who have the ability to make sound decisions based on knowledge and understanding. "Poor or no access to the Internet at home was raised as an issue that might advantage some students over others. Limited bandwidth, particularly as increasingly more devices share existing capacity, was raised as a challenge. Teachers were worried that the school may not have enough infrastructure to handle an increase in Wi-Fi use; also noting that fluctuations in the amount of data that can be downloaded occurs throughout the day and, in turn, there is no consistency in what one can expect to do with students on the devices.

\section{High School Teachers}

According to the high school teachers, one of the key potential outcomes of using tablets and other digital technologies in the classroom is collaboration - both at a school-wide level and in the classroom, because users can more easily share documents. For example, group activities can take a lot of class time since the students are unable to do the activity at home (i.e., teachers cannot expect the students to coordinate outside of class); but with tablets students can collaborate remotely, turning the devices into collaboration tools. Another example comes from a teacher who assigned a jigsaw class activity with nine questions. The students were divided into nine table groups, each getting one question and sharing the same document with all other groups. The kids used a Google doc template and were able to collaborate without needing computer lab time for the activity.

Teachers remarked that in the one-to-one classroom environment tablets can be used with additional hard and software as powerful tools for collaborative work. One example for such a tool was Padlet: a virtual wall that works like an online sheet of paper where users can put any content (e.g. images, videos, documents, text) anywhere on the page, together with anyone, from any device. The tool does not require specialty apps; users just sign in. Students would be able to read articles, answer questions and then share those with other students who chose different notes - others can benefit from the summary of the article without having to read the article itself. The tool is inclusive and provides a great way to offer choice, which in turn, increases engagement.

For special education students who may struggle with writing or with finding information, tablets provide easier access to helpful content and, in turn, levels the playing field with nonspecial education peers. Some special education students who have difficulty with penmanship may struggle less when typing as opposed to trying to write, which, in turn, helps them to keep the same pace as other students. 
The high school teachers echoed the middle school teachers concern about strict filtering of content. However, teachers also said that in managing classrooms, there are going to be problems -- regardless of whether or not technology is present. Teachers mentioned the reality that almost all of the students now carry smart phones, allowing those who do to break through filter restrictions, making the presence of content filters a selective barrier to information gathering for students without smart phones. One teacher expressed this by saying "...we are educators in 2016 and digital citizenry is part of our task as teachers." Teachers expressed that concerns regarding access to information should be addressed going forward, and voiced a need for curricula that help navigate this "new world" of ubiquitous digital technology and access to information.

Some teachers stated that they did not see it as their job to teach about technology/digital citizenry since they are teachers in a discipline (such as physics, chemistry or any other subject for that matter). In turn, there was some debate as to who is responsible for teaching digital citizenship and where within the school day this might best be done. There was general support for a notion that teachers should not be required to incorporate digital citizenship (or digital technology) into their classroom. As one teacher said, "Don't force it on those who don't want to use the devices." Instead, tablets and associated pedagogies ought to be part of a widening set of tools made available to teachers. The sentiment was not, however, that teachers might not ultimately embrace and utilize the technology. Teachers expressed the notion that we are living in an information age, where education is moving away from memorization of facts toward a need for working with information at is at one's fingertips (critical information literacy). Hence, there was recognition that digital technology is not just useful, but almost essential, yet that adoption by teachers would be more effective and less prone to conflict if based on a voluntary basis. Hence, teachers felt that support is needed for those teachers who want to use tablets to enrich their curriculum and make it more engaging. It was also noted that those teachers who choose not to use the tablets might get pressure from students to use it and they should be able to, at a minimum, submit assignments electronically. 


\section{RESULTS - Students}

The technical problems, including problems with the filtering, stood out as a dominant concern for students. The students also expressed great concern about how other students misused the iPads as a distraction from doing their work. It was apparent that they had not discussed many of their concerns with their teachers or parents and the focus group was hence a welcomed opportunity to have their voice heard.

In general, elementary school students enjoyed using the iPads especially for games. They indicated that their teachers are using iPads often for math games. The middle school students were overall negative about the experience with the iPads, and expressed frustration with implementation; but each student also made the effort to generate some positive aspects of usage as well. For instance, they shared that they liked the ability to share products with other students for feedback and encouragement. They also appreciated the different apps available and their 'freshness' as learning tools, but at the same time they were frustrated by the limited availability of apps and the inability to keep up with new or improved app developments. They also expressed concern over the fact that technical glitches, like slow or disconnected Wi-Fi or batteries dying, can ruin a lesson or activity. Students even admitted to the tablets being a distraction for themselves and others -- when they are supposed to be working, it is very easy to quickly access a game, a text message or email, or a different app and in many case, they suggest, the teacher is completely unaware.

The high school students were also candid about the difficulties they faced adopting the tablets in their classrooms, and they had strong opinions to share. All of the high school focus group participants were $9^{\text {th }}$ graders who had "a lot of experience" using tablets in middle school. They expressed that they were more experienced than their teachers at using the technology in terms of navigating applications, knowing what the possibilities were in using the technology, and being able to circumvent administrative "blocks." The group conversation focused heavily on the struggles that came with the tablets and changes that could be made to the current system. Highlighted difficulties include students distracting themselves and others through misuse and "wasting time" with technology troubleshooting during class time. The students had several suggestions for improving the student experience, and most of them involved better preparation on the administrative side before students are given access to the tablets (e.g., blocking sites, training teachers, setting up apps ahead of time, addressing technology issues outside of teaching hours). As for the "pros" of using tablets in the classroom, the students' mentioned ease of access to tools and opportunities for convenience that they would not otherwise have.

Below is a summary of the pros and cons that cut across all of the student focus groups:

PROS (and favorite things):

- Tablets take away the need to carry textbooks. 
- Assignments can be typed up and worked on at home and at school without struggling with file compatibility.

- Typing up assignments on apps like Pages, instead of having to go to the library or computer lab and being able to type rather than write is easier for many and, in turn, takes less time.

- Convenient for students who do not have similar technology at home.

- Being able to have extra time to work on assignments (can make a time later in the evening, rather than rushing to finish at the end of the day).

- Turning in assignments with apps like Showbie.

- Being able to download instead of printing documents and carrying them.

- Using tablets for graphics and video, as well as hobby or extracurricular work access to tools they might not otherwise have.

- Being able to enlarge text when working and writing.

CONS (and difficulties):

- School wireless connection is slow.

- The filters give students different search results at home vs. at school.

- Experience students can circumnavigate filters.

- Distraction and time spent off task. For example, students may play games and are not paying attention to instruction, something teachers may not notice. Students can easily switch tabs and hide an activity.

- Waiting for system updates is considered a waste of time.

- Students feel they know more about the technology than their teachers and are, in turn, more confident at using the technology. And, they feel their expertise is not utilized sufficiently.

Students also offered suggestions and solutions to the difficulties they have encountered, as indicated below:

- Put more time into blocking things permanently and making sure the blocks work.

- Instead of having an iPad for everyone, have classroom sets that teachers can request; seems wasteful to have them when not everyone uses them the same way or to the same extent.

- Allow students to use their own apple ID in order to avoid difficulty logging in.

- Teachers are not realizing that they can lock screens to control which apps are open or not, so make sure teachers understand the full extent to which they can control student access.

- Address technical issues outside of class time, which will keep teachers from getting frustrated in class, wasting time in class, and messing up schedules.

- Delays in getting the iPads was frustrating, so make sure everything necessary is done before the school year starts (e.g., ensure there is consistent access across all iPads and that all of the applications needed are present on all iPads). 
- Give students a choice on whether they get to use them or not for some specific tasks such as writing. Some students suggested that they can write a lot faster than they can type on a touch screen or keyboard (and availability of keyboards was sparse); other students said that typing was easier than writing. 


\section{RESULTS - Administrators and Parents}

\section{Administrators}

A total of seven interviews were conducted with CSD administrators (e.g., board members, principals, superintendent). The interviews indicate that the administrators have a basic understanding of what the school district's overarching goals are for this program (e.g., tablets as instructional tools to promote and enhance learning; not about replacing teachers; desire for students to be at or above grade level in various subjects and to ultimately graduate; increased access and to close the opportunity gap). Several of the interviewees also addressed their own personal goals related to the use of tablets in the schools (e.g., focus on students with disabilities; supporting students to be bi-literate and bi-cultural). All but one of those interviewed believed that the program is worth the investment; the one who was not sure whether it was worth the investment stated specifically concern about the 1-to-1 aspect of the program in high school as potentially wasteful due to potentially low usage. In addition, there was sentiment that there is not a need for all teachers to teach the same way with the same tools.

\section{Parents}

While there was an attempt to gain data on parental attitudes towards the "Tablets in Classrooms" pilot program, there was very little response to our efforts for creating focus groups, likely due to miscommunication with parents during the recruitment phase of the study. Nonetheless, the focus groups revealed some important insights, mostly around parental concerns with tablet use in general and in schools, and around the need for communicating with more detail around the program.

Parents generally felt positive about the program indicating greater engagement with their children's learning and their child feeling "proud" to share work with their parents. These parents felt lucky to be at a school where their kids get opportunity to work with modern technology. Parents also felt that not having to carry around heavy school bags' was a major benefit. Concerns raised by parents related to fears about breakage, theft, loss or misuse of the devices by children. Another key concern for parents was related to the costs; many of the parents felt that the initiative did not represent good value for the money. In particular, they were concerned about the lifecycle of the machines and the "never-ending" expenses for future upgrades. One parent felt "bullied" into participating in the tablet program, with no alternative given, or choice to opt out, and also expressed a lack of communication about how and how often tablets are being used in the classroom.

Other parents - particularly those of young, elementary school learners - expressed concern that their children's increased use of technology might be somehow detrimental. They expressed some concern around unintended harmful effects of using tablets excessively (e.g., can lead to more sedentary lifestyle; transitioning out of using tablet is hard for kids; vision issues; some parents don't know how to put limits on the new technology; kids cannot sleep as 
well), extending private concerns about their children's use of this technology to schools. Parents were unclear as to how much interaction their children are having with tablets and for what purposes. Better communication and support for parents will likely alleviate those concerns. There was also some tension expressed around the use of these tools for productivity versus entertainment. One parent described feedback from her kids that if they have an assignment to use the tablets, they feel the teachers just give them a website or activity to "entertain" them. On the other hand, one parent shared a story about when he volunteered for his child's kindergarten class and how the children were "super excited" about showcasing the iPads. He also mentioned that they used a mini-tablet at home everyday with their child for enrichment over the summer and the child chose to do about 30 minutes per week of math using Raz Kids and IXL; they also took advantage of a wide range of reading materials related to numerous different subjects. Another parent echoed this, saying that the digital experience at home is complementary to the work they are doing at school. Parents felt confident in helping their children use the tablet to support learning in the home, using, where school issued tablets are not available, their own personal technology at home. In the end, it seemed that the biggest issue for parents was around the amount of screen time their children are receiving and whether tablets were used in pedagogically productive ways.

When asked "What would be convincing evidence that embedding technology into the school experience benefits student learning without creating unintended harmful effects?" responses included:

- Clear, detailed and well-planned information about how tablets will be used to enhance learning helps to build confidence in parents.

- It is part of the responsibility as a parent to engage with the process. Parent-teacher relationship goes both ways.

- It is really helpful for teachers to communicate regularly and to build in information about the technology initiative (e.g., reminders about passwords).

- Provide a platform for parents to ask questions of other parents and to share relevant information and ideas (e.g., how are they managing technology with their kids; what works, what doesn't and why). Also, utilize PTA's and already planned parent events for parents to share how they are managing technology in general.

Discussions with parents suggest that key questions for parents relate to the benefits and implications of tablet use (e.g., how they will be used to support teaching and learning generally; more practical concerns relating to use, misuse, security, lifecycle, training and support and, costs). In this respect, ongoing engagement with parents that includes opportunities to discuss and negotiate approaches to implementation, as well as to learn more about the benefits of the tool could have a significant impact on acceptance and overall success of the tablet initiative.

Concerns from parents of English language learners were around how their native language, culture and traditions are not learned through tablets. In other words, the devices do not help students become bilingual or bicultural. As such, there was fear that the new technologies are hindering cultural identity. Most, however, recognized that digital citizenship may be important in 
high school and possibly, middle school, but felt that it was not essential for younger students. Concern was raised that some families cannot afford digital technology at home or that it is not a priority for them to embrace digital technology. Another issue raised was around awareness (or potential lack thereof) for limiting screen time. Parents of ELL students expressed the need for the CSD to make sure that translations of parent materials are culturally relevant and use language that is reflective of the cultural background of the families. They also cautioned against making electronic communication the dominant model for information sharing, noting the need for continuing send materials home in student backpacks, to send printed communiqué and not only electronic ones, and get important information out through parent-teacher conferences and PTA's. 


\section{Next Steps}

\section{Theory of Change}

Beginning with the knowledge gained from this study, as well as other previous evaluations, it is recommended that the CSD develop a mature theory of change to drive the next phase of this effort. A "Theory of Change" is a specific type of methodology used for planning, participation and evaluation, which aims to promote social change. More specifically, Anderson (2005) defines theory of change as "a series of critical thinking exercises that provide a comprehensive picture of the early-and intermediate-term changes that are needed in order to reach a longterm goal articulated by the community." Ultimately, Theory of Change is a planning and issue framing tool as well as a monitoring and evaluation tool and it keeps the processes of implementation and evaluation transparent so everyone involved knows what is occurring and why. An effective, research-based Theory of Change process is a great tool for schools to use when strategically planning for technology initiatives.

A Theory of Change is essentially a concept map that describes a program or change initiative what it is, what it does and how, as well as how it is expected to lead to the desired outcomes and goals. Typically, outcomes and goals are mapped out in a Logic Model Framework, which provides the basis for identifying what type of activity or intervention will lead to the outcomes identified as preconditions for achieving the long-term goal. Appendix D provides an initial, draft Theory of Change and the accompanying Logic Model for the CSD Tablets in Schools Program, derived from the results of this study.

Recommended next steps in this process include for CSD decision-makers to use the provided draft versions of a Theory of Change / Logic Model as a starting point for a consensus process that involves school leaders, teachers, students and select parents. Following agreement on a final version, the district (with potential help from outside experts) can develop a plan of action that tests the change theory, i.e., an impact evaluation that shows whether the tablet program is achieving agreed upon outcomes and goals via the mechanisms (the program) that has been put in place.

Communication is another key element in the process; involving stakeholders in the development of the final version of a Theory of Change invariable requires continued engagement and provides a maximum level of transparency around the program, its goals, its implementation and its impact.

\section{Considerations for Next Steps}

Throughout this research, we have heard the CSD community advocate for a holistic, iterative, effective approach toward technology and learning. As mentioned previously, further programming should be guided by pedagogical insights and an overall sound theory of change. 
Hence, we frame some of the key outcomes from this report in the form of discussion questions, meant as scaffolds for productive dialogue about technology integration in the CSD among a broad range of stakeholders.

- Exactly how will the use of technology contribute to improved learning outcomes? Has the CSD agreed on a credible theory of change, rooted in experience and education research outcomes, that suggests precisely how technology-related activities lead to better learning outcomes? And what are these learning outcomes?

- How will change over time be measured? What are realistic expectations for change over time in participating teachers' and students' knowledge, skill and attitudes? How will learning gains be measured and is there any comparison group to ensure that change can be attributed to the program?

- What is the nature of teacher professional development, or teacher learning? What is the best approach to professional development and growth (long-term vs. shortterm; subject-related or pedagogically-focused)? How will enough time be made available for teachers to participate in a sustained way? How motivated are they to do so? Is there provision for certification? And, is a process that strengthens teachers' abilities to use tablets (and other technology) in the classroom conducive to support teachers in other ways as well?

- Is communication and community engagement systematic, effective and reliable? What are the means for collecting and reporting insights and critical reflection, and for providing continued feedback?

These questions can guide the next phase of the program, which will likely consist of a plan to scale promising practices in using tablets and other digital technology to all classrooms, and to ensure a sustainable path forward for the continued adaption and adoption of new technology in CSD is guaranteed. 


\section{Conclusions}

Tablet use in the classroom is clearly changing the way educators teach, how students learn, and the way teachers and students (and their parents) communicate. Tablets certainly have the ability to make learning more productive and flexible. Both administrators and teachers reported observing improvements in test scores, accelerated comprehension, and expanded engagement of students. One issue made very clear by the respondents is that integrating technology into the classroom takes much more effort than simply handing out devices. As such, it is important that the CSD continue to be aware of the realistic costs and necessities of using tablets and other mobile devices in their K-12 classrooms.

It is also important to recognize that the more a teacher uses technology, the more comfortable they will be with the technology in their classroom, and this is independent of age or years of teaching (Costley, 2014). One of the most interesting outcomes from this research is the number of classroom teachers who, with a little hands-on support, created technology-rich lessons with a minimum of training or professional development. Yet, it is also very clear that a combination of more training and support can result in a more successful and innovative learning experience for teachers and their students.

The Corvallis School District did not dictate how teachers should use the devices or what to use them for; individual teachers could go at their own pace. This approach is viewed as a positive aspect of the program by some (i.e., those who want this freedom), and a negative aspect of the program by others (i.e., some needed more guidance and direction). The teacher survey has led us to understand that while many teachers would like to use tablets meaningfully in their classrooms, they are not able to due to a lack of time, access, or training. At the same time, research findings clearly indicate that tablets are being used by many teachers to support a diverse community of learners at every grade level. Students are using the tablets for long-term projects and in daily core subject reviews. More specifically, tablets are being used as a research tool; for reading books; practicing math; writing reports: vocabulary review; for creating videos, podcasts and slide shows; and the list goes on. In addition, the tablets have helped engage students, cut down on paper, and allowed absent students to keep up with classwork.

Integrating technology in education has its advantages and disadvantages; proper implementation and planning is key to minimizing the drawbacks. Overall, the change in student learning and instructional changes are aspects of the program that warrant further discussion, in addition to the need for training, support, and improved communication by the CSD. A Theory of Change is a powerful communication tool and framework for reaching long-term goals. It is a useful communication and planning tool for schools, in particular, where decisions affect many individuals, groups and programs. This process should be used to amend a Corvallis School District Technology plan moving forward. 
Finally, it is useful to recognize that no technology has an impact on learning in its own right; its impact depends upon how it is used. Tablets are no exception to this and in this report we identify ways in which these devices can be used to support teaching and learning. There is evidence that they can help teachers, learners and parents in multiple ways. To leverage these learning benefits, the tablets should play the supporting role to the learning activity (i.e., rather than ask 'Can tablets support learning?', instead ask 'How can tablets be used to support collaborative, exploratory or personalized learning?'). Another important benefit is that learning is not restricted to specific disciplines; tablets and similar technology allow students to develop the necessary skills to become critical digital citizens, an aspect of the tablet program that many teachers highlighted.

The tablet is one of many tools that can assist in learning, and when used wisely it can be quite effective. As with all technology, however, this is not a one-off decision -- the on-going costs and the need for on-going evaluation and monitoring should not be underestimated. Tablets should also be seen within the context of rapidly changing technology. This study identified affordances of digital technology, lessons learned from the use of tablets, and potential challenges, which can transfer to the next evolution of digital devices that invariably follow and replace tablets. 


\section{References}

Anderson, A. (2005). The community builder's approach to theory of change: A practical guide to theory and development. New York: The Aspen Institute Roundtable on Community Change.

Costley, K. C. (2014). The Positive Effects of Technology on Teaching and Student Learning. Arkansas Tech University - Curriculum and Instruction.

Herold B. (2016). Technology in Education: An Overview. EducationWeek.

http://www.edweek.org/ew/issues/technology-in-education/ (last accessed January 2017).

MCH Strategic Data. (2012). Technology Use in Nation's School Districts.

http://mchdata.com/mch-survey-results-technology-use-in-nations-school-districts/ (last accessed December 2016).

National Research Council (2011). Learning Science Through Computer Games and Simulations. Washington, DC: The National Academies Press. doi: 10.17226/13078.

Pearson (2015). Pearson Student Mobile Device Survey 2015 - National Report: Students in Grades 4-12 http://www.pearsoned.com/mobile-survey-2015-grades-4-12 (last accessed December 2016).

Reidinger, K. \& Storksdieck, M. (2016). Use of digital technology in classrooms. Results of a front-end study. Unpublished technical Report. Corvallis, OR: Oregon State University. 


\section{Appendix A: Methodology}

In order to answer the research questions, capture a variety of perspectives on the program, and to craft a Theory of Change for the use of tablet computers as learning devices in Corvallis schools, we engaged three key stakeholder groups - teachers, students, parents - in a series of moderated, focused group discussions ("focus groups"), conducted face-to-face semi-structured interviews with key representatives from teacher unions, parent groups, school administrators, and school board members, and conducted a survey with all teachers in the Corvallis School district around the use of tablets as learning and teaching tools.

\section{Survey with Teachers}

The CRL team constructed a short questionnaire around the use of tablets in the CSD, which was administered to all teachers. The survey used two questionnaires: one for elementary and middle school teachers (where tablets have already been introduced), and a separate one for high school teachers (where tablets will be introduced this year). The survey fulfilled two key functions: It informed all teachers of the study, and it provided all teachers an opportunity to give feedback. The survey asked teachers to rate their own use of tablets, their attitudes towards tablet use, and their experience with the current program.

\section{Five Focus Groups with Teachers}

Five focus groups were conducted as approximately 60 -minute discussions. Teachers were identified by the school district with help from the CRL staff and the results of the teacher survey. Each focus group represented a "typical" sample and were conducted with the following groups: Mountain View teachers; middle school teachers - mixed group; high school teachers non-users; elementary teachers - mixed group; and high school users. We did not aspire to capture a full representation of all members of a class of audiences.

\section{Three Focus Groups with Students}

Focus groups were conducted as approximately 30-minute discussions, with assent from students and written permission by parents, as appropriate. Students were identified by their teachers with help from school district and Center staff. We conducted three student focus groups: A group of 3-5 graders from Mountain View Elementary, a group of middle school students from Linus Pauling, and a group of freshman students at Crescent Valley High School who had used tablets during their middle school years.

\section{Two Focus Groups with Parents plus one interview}

Focus groups were conducted as 30-60 minute discussions. Parents were recruited by teachers and school district staff. We expected three focus groups that represented the focus groups conducted with students, but response was not as strong as expected and we only conducted one focus group at Mountain View Elementary, in addition a one-on one interview was held with a PTA leader and a short survey (5 questions) was distributed to PTA members from Garfield 
Elementary. Due to the low parent turnout, we strongly recommend that the CSD find an alternate way to glean parent input (e.g., community discussions, short parent survey).

Semi-structured, in-person interviews with key stakeholders

Seven representatives from teacher unions, school administrators (including principals), and school board members were identified by district and Center staff and recruited to participate in an in-depth, one-on-one discussion on the opportunities and challenges of tablets in classrooms. Interviews lasted approximately 60-minutes. 


\section{Appendix B: Summary of Key Findings from the CSD Tablets in Classrooms Research}

\begin{tabular}{|c|c|}
\hline \multicolumn{2}{|c|}{$\begin{array}{c}\text { Top Pros and Cons } \\
\text { (Please note: these are not one to one relationships) }\end{array}$} \\
\hline $\begin{array}{l}\text { Pro 1: Access to... } \\
\text { - } \text { Current information } \\
\text { - } \text { Much more content (e.g., online } \\
\text { resources) } \\
\text { - New software and apps }\end{array}$ & $\begin{array}{l}\text { Con 1: Infrastructure/Technological } \\
\text { Limitations } \\
\text { - The technology is constantly changing } \\
\text { - Need to be up and ready with Wi-Fi } \\
\text { and broadband width, etc. } \\
\text { - Need a robust filter to limit access } \\
\text { - Security concerns (e.g., use of } \\
\text { - } \text { ersonal id's) } \\
\text { - Spgrades hit right as trying to roll-out } \\
\text { Sometimes difficult to log on }\end{array}$ \\
\hline $\begin{array}{l}\text { Pro 2: Differentiated Instruction } \\
\text { - } \text { Provides the kids that get it the ability } \\
\text { to move on, whereas struggling } \\
\text { students can break out into small } \\
\text { groups } \\
\text { - } \text { Teacher can dynamically change the } \\
\text { delivery of content } \\
\text { - Can transition from 'pull out to push in' } \\
\text { (classroom is a social unit and don't } \\
\text { want to pull kids out that require special } \\
\text { education) }\end{array}$ & $\begin{array}{l}\text { Con 2: Classroom Management } \\
\text { - So many attractive nuisances (e.g. } \\
\text { sports, video games) } \\
\text { - Disengaging }\end{array}$ \\
\hline $\begin{array}{l}\text { Pro 3: Replicates Real-World } \\
\text { Application } \\
\text { - Ability to focus on what is relevant } \\
\text { - Simulates the ways professionals } \\
\text { - } \text { work today } \\
\text { - Nitical Thinking } \\
\text { - } \text { Able to adapt }\end{array}$ & $\begin{array}{l}\text { Con 3: Safety/Risks } \\
\text { - Need better understanding and } \\
\text { guidance related to effects on health } \\
\text { - Where tablets should be placed } \\
\text { (ergonomics) } \\
\text { - Screen time limits (good vs. bad); } \\
\text { electromagnetic flux }\end{array}$ \\
\hline
\end{tabular}




\begin{tabular}{|c|c|}
\hline $\begin{array}{c}\text { Pro 4: Supports Special Needs } \\
\text { - Equal access } \\
\text { - } \\
\text { No identifier that student is special } \\
\text { - } \text { Apps to target special needs }\end{array}$ & $\begin{array}{l}\text { Con 4: Teacher Readiness and Support } \\
\text { - Many teachers do not know how to use } \\
\text { the technology } \\
\text { - Need to train teachers and make them } \\
\text { accountable } \\
\text { - Provide ample planning time and } \\
\text { professional development }\end{array}$ \\
\hline $\begin{array}{c}\text { Pro 5: Personalized Learning } \\
\text { - Able to navigate world } \\
\text { - Higher level of independence }\end{array}$ & $\begin{array}{l}\text { Con 5: Communication and Outreach } \\
\text { around Program Goals } \\
\text { - Need to better ensure that the teachers } \\
\text { and parents understand the program } \\
\text { goals; buy-in } \\
\text { - Alleviate fears }\end{array}$ \\
\hline $\begin{array}{l}\text { Pro 6: Digital Citizenship } \\
\text { - } \text { Prepares students for a society full of } \\
\text { technology } \\
\text { - Teaches kids the norms of appropriate, } \\
\text { responsible technology use }\end{array}$ & $\begin{array}{c}\text { Con 6: Difficulties of Change } \\
\text { - Need to be sure that this is adaptive } \\
\text { - Need to recognize that change is hard } \\
\text { - Negative experience exacerbates } \\
\text { disinterest in using new technologies }\end{array}$ \\
\hline $\begin{array}{cl}\text { Pro 7: } & \text { Teaching Tool } \\
\text { - } & \text { Tablets replace textbooks } \\
\text { - } & \text { Shift from memorizing to active } \\
& \text { learning } \\
\text { - } & \text { Tool for substitution, augmentation } \\
& \text { (doing additional activities), and } \\
& \text { modification of content (creating new } \\
& \text { tasks and refining content) } \\
\end{array}$ & $\begin{array}{l}\text { Con 7: Kids Can't Afford to be Plugged } \\
\text { in Constantly } \\
\text { - Brain research shows benefits of } \\
\text { silence and down time } \\
\text { - Over-saturation of sensory input }\end{array}$ \\
\hline $\begin{array}{c}\text { Pro 8: Collaborative Learning } \\
\text { - Students can work with others } \\
\text { - Multitude of delivery mechanisms }\end{array}$ & $\begin{array}{l}\text { Con 8: Access } \\
\text { - Some students don't have access, or } \\
\text { - have limited access, at home } \\
\text { - } \text { Easy access to off-task material } \\
\text { Potential for an overwhelmed teacher } \\
\text { - } \text { Mo just 'plug students in' } \\
\text { More distractions }\end{array}$ \\
\hline $\begin{array}{l}\text { Pro 9: Language Learning and } \\
\text { Development } \\
\text { - Numerous language learning apps } \\
\text { - Can monitor progress and see how } \\
\text { students need extra support }\end{array}$ & $\begin{array}{l}\text { Con 9: Cost } \\
\text { - Who pays for the insurance on each } \\
\text { device? CSD? Parents? } \\
\text { - Purchase viewed by many as zero sum } \\
\text { game (expensive; money could be } \\
\text { reallocated elsewhere) } \\
\text { - } \text { Many students do not need a device } \\
\text { and, in turn, there is money being } \\
\text { wasted by giving students one more } \\
\text { tablet (when they already have one). }\end{array}$ \\
\hline
\end{tabular}




\begin{tabular}{|l|l|}
\hline $\begin{array}{l}\text { Pro 10: More Comprehensive, } \\
\text { Integrated Classroom Experience }\end{array}$ & $\begin{array}{r}\text { Con 10: Teaching Tool } \\
\text { - Helps students differentiate between }\end{array}$ \\
$\begin{array}{l}\text { Niases and unbiased information } \\
\text { still need well-developed lesson plans }\end{array}$ \\
- Less need for printing costs & $\begin{array}{l}\text { The technology doesn't take the place } \\
\text { of good pedagogy }\end{array}$ \\
- Higher level of independence for & \\
- learners & \\
- Eurriculum integration & \\
- Technology augments instruction & \\
- Transforms how teachers provide & \\
instruction &
\end{tabular}




\section{Appendix C: Promising Practices Using Tablets and Apps in the Classroom}

From taking notes to taking pictures; tuning into satellite radio to going on a virtual field trip, there is no single way to use tablets in the classroom. Below is a descriptive list of promising practices and top apps that Corvallis School District teachers and students shared as part of this research. The list is based on the most creative, functional, and innovative uses of tablets (listed in no particular order).

\section{Math}

Math teachers need to create an environment that maximizes students' learning opportunities so that they can encourage self-directed learning, model mathematical thinking and reasoning, and provide purposeful and timely feedback. Tablets, and associated math learning apps, provide teachers with more opportunities to reach these goals; they are also convenient and engaging for students. In addition to the app features listed below, teachers use tablets to access spreadsheets, practice equations and strategies, conduct small group work, and access self-paced math games.

Popular Apps:

- $\quad$ ST Math is a research-based, visual math instruction app developed for learning math solution in K-12 environments.

- $\underline{\mathrm{IXL}}$ is an adaptive math practice program which includes review and games.

\section{Test Taking and Practice}

There are many ways to use tablets in order to aid students in taking tests. CSD teachers are taking full advantage of the ability to use quick response drills to practice for STAR

(Standardized Testing and Reporting) testing, for compiling questions for a quiz, or to test the knowledge of their students against artificially intelligent apps (e.g., Siri or Google Now). For example, one teacher described how he has students 'race' to see who can answer particular questions first. Or, they can write down their answers in advance and search online to see if they are right.

Popular Apps:

- Quizlet offers learning tools and flashcards.

- Socrative is a test review app. Teachers can get instant insight into student learning with easy-to-create quizzes, polls, exit tickets and more.

\section{Exploring the World}

Students can use their tablets to navigate around the world; they can learn about different countries, look at the solar system, and even map out basic travel routes. 
Popular Apps:

- Google Earth allows students to view satellite imagery, maps, terrain, 3D buildings, galaxies far in space, and the deepest depths of the ocean. And, it lets students see the contours and landmarks of the planet.

- Wikiplaces is a collaborative mapping project with the aim to describe every location in the world. It currently has over 25 million places annotated all over the world, many of which contain detailed descriptions, photos and user comments.

- Apple's Maps includes a detailed 3D-flyover for some major cities (the options appear automatically when available).

- Google Maps is a web mapping service offering satellite imagery, street maps, $360^{\circ}$ panoramic views of streets, real-time traffic conditions, and route planning for traveling by foot, car, bicycle, or public transportation. It has recently added 3D buildings in some areas, as well.

- Starwalk is an augmented reality app that labels all the stars, constellations and satellites. Users can simply point an iPad and real-time motion tracking identifies the overhead stars.

- Arloon Solar System is an interactive 3D tool that lets students discover and explore the solar system.

- Planet Earth HD is a comprehensive, interactive eBook that provides information on the continents, weather cycles, the solar system, and more.

\section{Literacy and Reading}

Literacy applications can improve the reading preparedness of younger students, as well as second language learners. Reading on a tablet is like reading a book, although some apps are more like interactive movies (with animations and clips). Many CSD teachers acknowledged improvements in reading skills as a result of particular apps. Additional uses include: access to online magazines, listening to books, reading digital books in Spanish, accessing electronic textbooks, independent reading, reading comprehension, vocabulary review, and phonological awareness. One teacher described how they have students create a collage of culture using online magazines (related to students' culture or interests).

\section{Popular Apps:}

- iBooks has an extensive audiobook library.

- Read Naturally offers reading interventions.

- Raz-Kids is an interactive reading program.

- Newsela provides recent news articles.

\section{Bilingual Education}

Schools are more diverse than ever and educators must adapt to students that are not predominately English speaking. At the same time, most children have the capacity and facility to learn more than one language. And, there is a growing body of research that suggests 
students who are bilingual have advantages (e.g., literacy development, improved problemsolving skills). This makes bilingual learning an important component of in the $\mathrm{K}-12$ education system.

\section{Popular Apps:}

- Duolingo is a free language-learning platform that includes a digital language proficiency assessment exam.

\section{Assessment}

Tablets allow for cost effective delivery and reporting of results and make it possible to weave assessment into the daily routines. For example, daily quizzes can be administered electronically and graded instantly, giving a real-time picture of subject mastery. In addition, all information goes instantly to centralized systems that can report back on progress and trends, allowing educators to take the most effective actions possible before students get too far behind. Teachers can also evaluate their own teaching. For example, if most of the class is answering a question incorrectly then perhaps the teacher missed explaining something.

\section{Popular Apps:}

- Seesaw is a relatively new app offering a suite of tools that enable students to keep a record of what they are learning (and parents, as well). Photos, videos, drawings, text, web links, pdfs and material from other apps can all be incorporated, and teachers have the option to log into the journals (and approve work) from any device. A recent update added blogging capabilities to the app.

- Google Forms allows teachers to customize data collection. Customized forms can be used for classrooms observations or for identifying students' goals and objectives and to see if they are meeting them or not. Teachers (and others) can also evaluate how much time was needed to reach goals and can provide instant feedback to the students. One CSD teacher created Google Forms to monitor homework, while another recorded notes from conferences. School administrators can also use it to track how much time they are in certain classrooms so they can see where there are gaps.

- Socrative can be used for quick or traditional quizzes. One CSD teacher described how before class, she creates quizzes for students and the website automatically divides the class into teams; it also gives percentages which can be used as a grade.

- Kahoot allows teachers to build quizzes or create flashcards for review. They can also embed videos and use Kahoot as part of the teaching process. Students can also create review games to share. One disadvantage is that students can use aliases. And, while the teacher can see overall how the class is doing, unlike Socrative, they cannot see the patterns of a struggling student.

- Edmodo is a tool for collecting student work and assigning quizzes. Edmodo can lighten the load of paperwork teachers take home. It is easy to set up student accounts, assign 
them to different classes, create and assign quizzes, and have students upload attachments of files they have created.

- Showbie allows teachers to assign, collect and review student work, then provide detailed feedback, either individually or collectively, using annotations, text notes and voice notes directly onto students' documents. Showbie allows students to turn in work and they are able to enlarge and see what they typed (for visibility) or annotate. One benefit described by a CSD teacher is that with Showbie students are more accountable. Another teacher mentioned a downside of Showbie is the need to download an assignment and then re-name it, making it more difficult than Classroom.

\section{Assisting Special Needs Students}

Tablets can be used as communication tools by improving the interaction between teachers and students with cognitive disabilities. There are numerous apps that can assist students with speaking or who have trouble understanding social situations. They also help students communicate emotions and help with conditions like Dyslexia. For special needs populations who struggle with writing and finding information having access to these apps gives them a more level playing field with peers.

\section{Popular Apps:}

- Dragon is a speech recognition app. Students can speak and Dragon will transcribe what they say into text. For students who struggle with reading and writing, they can actually see their words in print.

- $\quad$ StoryBuilder is designed to help learners improve paragraph formation, integration of ideas, and higher level abstractions by inference. Extensive use of audio clips promotes improved auditory processing for special needs children with autism spectrum disorders or sensory processing disorders.

- MyHomework is a school organizer which makes it easy to keep track of what tasks and assignments need to be done. It is particularly helpful for students who have trouble concentrating.

- Speak It! Is a text-to-speech app that can help learners read or speak. Students simply copy and paste selected text and Speak It! reads the words out loud. The app also highlights each spoken word so that kids can more easily follow along with the text. This app gives non-verbal students a voice so that he or she can interact with classmates.

- $\quad$ Notability is a note-taking app which works especially well with visual learners and those who excel through listening (via audio recording component).

- Social Skills Builder provides interactive videos that teach key social thinking, language, and behavior that are critical to everyday living. It specifically helps teach problem solving and friendship/life skills, critical thinking, emotions, and consequences. 
- $\quad$ eBooks can help students with dyslexia by allowing them to use the tablets to listen to books instead of struggling to read.

\section{Assignments}

Tablets allow for streamlined posting and submission of assignments.

Popular Apps:

- Dropbox allow students to learn about their homework assignments, as well as turn them in. The teacher can grade the assignment and return it to the Dropbox in a matter of minutes.

- Educreations is an app that transforms an iPad into a recordable whiteboard. It records voice and handwriting, and also allows users to insert pictures to produce personal video lessons that can be shared with students online.

Improving Communication and Collaboration

Digital tablets allow students and teachers to better communicate and collaborate.

\section{Popular Apps:}

- Edmodo is essentially a social media platform, which facilitates communication between teachers and students where they can hold discussions, post and turn in assignments, and have class discussions or debates. It also has grading and lesson planning features as well.

- $\quad$ Padlet is a virtual wall that allows people to express their thoughts on a common topic easily. It works like an online sheet of paper where people can put any content (e.g. images, videos, documents, text) anywhere on the page, together with anyone, from any device.

\section{Student Research}

Students can use the Internet on their tablets to complete class assignments and homework. They can also learn about current events or complete WebQuests. They can even keep up with the latest news from around the world.

\section{Popular Apps:}

- Newslea is a good resource for teachers and students to garner child-centered news. They cover science, money, law, health, the arts, kids, and have a section called war and peace. One can also adjust reading levels to differentiate the difficulty of text complexity.

\section{Student Presentations}

Tablets can improve student presentations by allowing students to record and practice public speaking. Many apps can also be used to do real-time drawing, writing, and animation during a presentation. Students can circle, highlight, or write in points as they present their latest 
research or findings. When they are done, the presentation is saved and can be emailed to the teacher for grading.

Popular Apps:

- Google Slides is an online presentations app that allows students to show off their work in a visual way. Users can create and edit presentations.

- Keynote makes creating posters and presentations, along with animations, easy. Students can simply touch and tap in order to put together a presentation, giving them accessibility to resources on an individual level and allowing them to articulate themselves in ways that include, but are not limited to, a written essay.

\section{Typing and Writing}

Tablets can help students practice spelling, compose documents, take notes, write and type final drafts, type and listen with speech to text, or make a book. Typing is faster than handwriting, which is helpful when there is a lot of information to take down. Research also suggests that students write longer texts when they learn to write on a keyboard, and that they become more motivated to write.

\section{Popular Apps:}

- $\quad$ Pages is a powerful word processor that lets users create documents. Features also allow for real-time collaboration.

\section{Immersive and Interactive Note-Taking}

Students' notes are an important tool for learning. Good note-taking practices can lead to more efficient study practices, improved learning outcomes, and increases in longer-term retention of content. Students can use a variety of note-taking apps to help them organize their thoughts.

\section{Popular Apps:}

- $\quad$ Apple Notes is a note-taking app which can incorporate web links, checklists, photos taken within the app, sketches and miniature maps. Students can use Notes to record what happens on a field trip, to research a particular event in history, or for any other purpose where different media needs to be mixed with text.

- Evernote is a full-featured app that stores all of its information in the cloud, meaning note files and clippings can be easily accessed from different locations and via multiple devices. There are also options for collaborating on notes with multiple people.

- Notability is a helpful app in which students can take handwritten notes, play back their notes with the audio feature, and import slides or anything else might they want.

\section{Classroom Management}

Tablets help teachers keep track and be aware of each of their student's progress. Tablets can also help teachers get their students more actively involved in class and to better plan and create their lessons. Tablets allow teachers to distribute electronic handouts and assignments, 
and give students remote access to teacher websites; they can also submit assignments virtually. At the same time, teachers can virtually give or check grades on Pinnacle.

Popular Apps:

- Google Classroom is a blended learning platform for schools that aims to simplify creating, distributing and grading assignments in a paperless way. It provides quick accessibility for teachers, students and parents.

- Corkulous is a multi-purpose app containing cork boards where users can place notes, labels, photos, contacts, and tasks. Teachers can group ideas visually on one board or spread ideas out across multiple boards.

\section{Learning Games}

One way teachers have incorporated the use of tablets in the classroom is through the use of games. Teachers allow students to play games on the tablets as a supplement to a lesson and to reinforce learning. Games can help to connect ideas and increase engagement. Several CSD teachers suggest that incorporation of games lead to improvements in student learning and in their ability to remember key facts that are covered during the process of playing the game. Other teachers mentioned that the time and logistics of incorporating games can be a challenge, particularly if students cannot log on or get kicked out and have to restart. The competitiveness can be an issue as well -- the most competitive students are playing to "win" and not necessarily playing to learn.

\section{Popular Apps:}

- Kahoot is a game-based classroom response system, where teachers can create fun quizzes using Internet content.

- $\quad$ Angry Birds is an educational game which the elementary students reportedly enjoy. Teachers can use it for math (e.g., by assigning numbers to different colored birds and having kids do calculations) or physics (e.g., if a bird hits a structure at a certain angle where will it fall?). Students can also write stories about the game, design their own levels, or create related artwork.

\section{Worldwide Radio}

When studying a foreign culture or the like, access to radio stations from around the world provides a unique way of bringing a taste of it into the classroom.

\section{Popular Apps:}

- Tuneln Radio allows kids to experience music and talk shows from around the world in dozens of different languages, with more than 100,000 stations to choose from.

\section{Creative Photo-Taking and Movie-Making}

Tablets have camera apps that relatively simple to use and can record anything from a field trip diary to the results of a science experiment or a class art show. Most include a time-lapse mode 
for recording a scene over a long period of time and then allow for shortening the results later. There are also many other apps that enhance the ability to make and analyze movies or videos.

Popular Apps:

- $\quad$ Pic Collage for Kids, a safe photo editor which lets students put pictures together and add stickers on top. It offers numerous backgrounds, free stickers, and different fonts. Students can create collages and send them by email (or text).

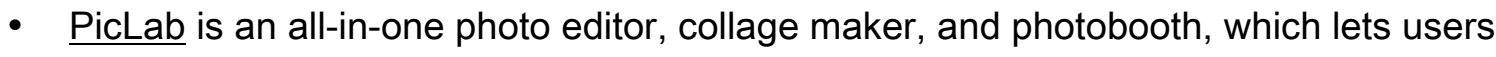
add filters, text and various other effects.

- $\quad$ Movie allows students and teachers to view, edit, and share movies.

- $\quad$ Stop Motion Studio allows users to build a movie from a series of pictures.

- Shadow Puppet Edu lets users add voice narrations, music and text to videos.

- $\quad$ ChatterPix Kids lets students turn inanimate objects and drawings into animated talking heads. They simply take any photo, draw a line to make a mouth, and record their voice. They can then share the Pix with others.

\section{Music-Making}

Tablets are popular music-making devices, and there are lots of apps available, ranging from ones that add effects to existing tracks to others that allow for composing something from scratch, note by note. Students can make music (or any other kind of audio) and then use a tablet to record it. Two CSD music teachers use iPads to record students playing music for auditions and for pieces they are playing for a grade. They mentioned that the iPads took the nervousness and fear factor out for the students and allowed the teachers to give clearer feedback.

Popular Apps:

- GarageBand allows students to use 'touch instruments' and create music with all the features of a modern recording studio. Teachers and students can also plug an actual instrument into the tablet and play along with special effects. Users can also record and edit third-party instrument apps and share results via email, Facebook, YouTube, etc.

- Music Studio offers a complete music production environment for iPads.

- $\quad$ Caustic 3 is a music creation tool; everything is real-time and optimized for mobile devices.

- $\quad$ ABC Music is an Apple app for younger students. It is aimed to nurture the musical creativity of kids.

- Animal Band is a 3D interactive music app that encourages young children to explore music while listening to their favorite tunes.

\section{Augmented Reality and Virtual Field Trips}

CSD teachers are beginning to see the educational value of virtual and augmented reality. Technology makes it so that students can afford to go virtually anywhere that they want. 
Teachers can utilize the various app and take students to national parks, or connect students with someone from another country to learn about their customs or get a tour of their local community.

Popular Apps:

- Google Expeditions allows teachers to take students on immersive, virtual journeys (e.g., coral reefs or the surface of Mars).

- Skype allows teachers to take students for an adventure without leaving the classroom by visiting experts out in the field all around the world.

\section{Creating Blogs}

Blogging is a great way to write and share ideas, and comes with the benefit of reflecting on what has been learned while at the same time creating an emotional connection to the information. Blogging offers many different opportunities for students to share their voice while becoming digital citizens. Through blogging, students become experts in the area they are reporting on and have the opportunity to process and think about each of their comments, allowing for deeper and richer conversations and debates.

Popular Apps:

- Easy Blog Jr makes web publishing easy by allowing younger students to log in by tapping on their picture (so it's suitable for shared devices), and they can then combine text, video and images into a blog post that goes live with a couple of taps.

- $\quad$ Blogsy is a more complicated alternative for older students with a host of extra capabilities.

- Blogger is Google's free tool for creating blogs. It includes hosting and analytics.

- Edublog allows students to manage and update blogs. They can post or moderate comments, upload photos and videos, and more. 


\section{Appendix D: Logic Model and Theory of Change for CSD Tablets in Schools Program}

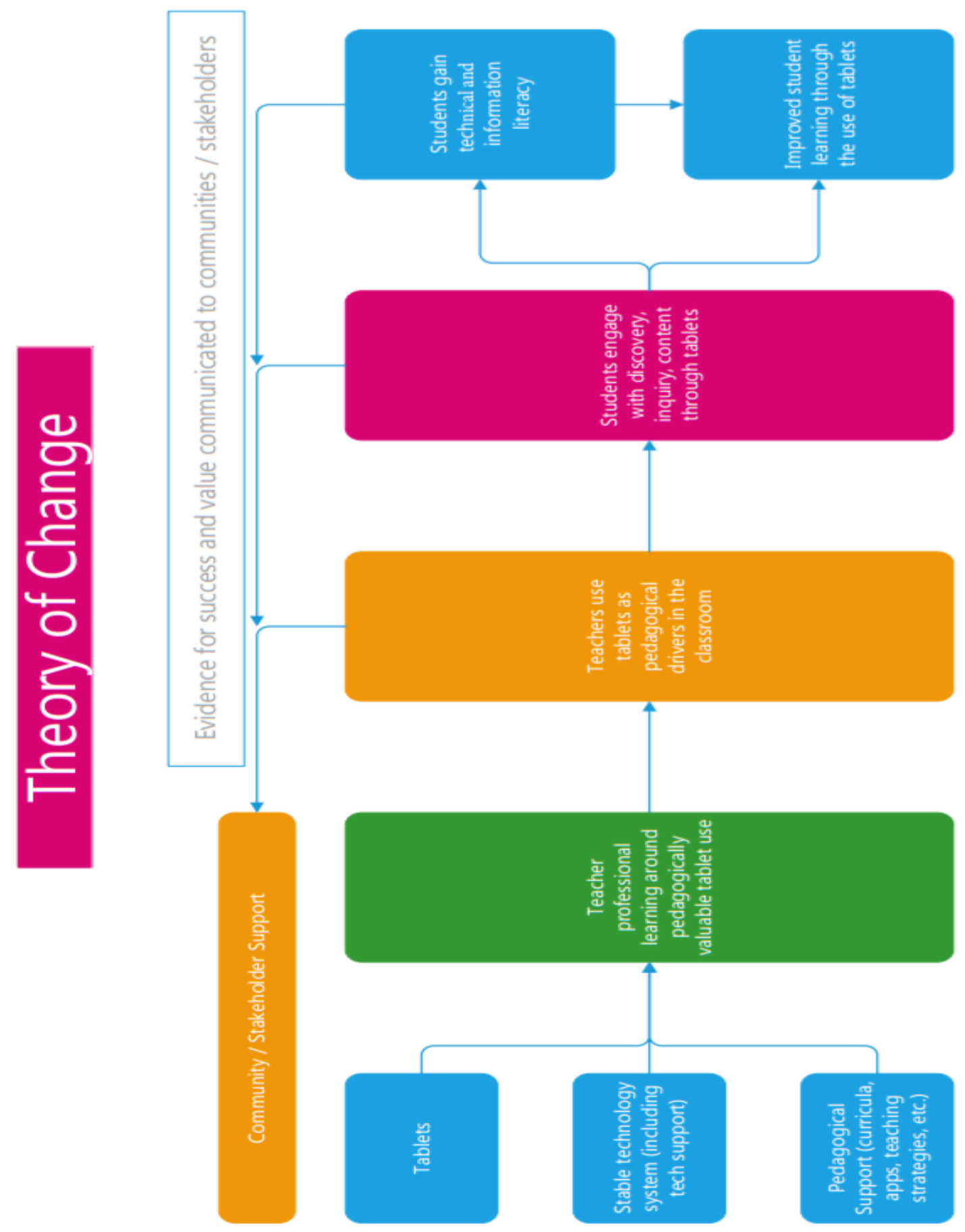




\section{CORVALLIS SCHOOL DISTRICT TABLETS IN CLASSROOMS PROGRAM LOGIC MODEL}

\begin{tabular}{|c|c|c|c|c|c|}
\hline \multirow{2}{*}{ INPUTS } & \multicolumn{2}{|c|}{ OUTPUTS } & \multicolumn{3}{|c|}{ OUTCOMES } \\
\hline & Activities & Participants & Short-term & Medium-term & Long-term \\
\hline $\begin{array}{l}\text { Resources (e.g., } \\
\text { money, } \\
\text { personnel/consultants) } \\
\text { Prior knowledge } \\
\text { (research, literature } \\
\text { review) } \\
\text { Community } \\
\text { feedback/support } \\
\text { Communication } \\
\text { exchange with } \\
\text { stakeholders } \\
\text { Infrastructure / } \\
\text { technology environment } \\
\text { System of teacher } \\
\text { professional learning }\end{array}$ & $\begin{array}{l}\text { Provide } \\
\text { Tablets/iPads } \\
\text { Teacher } \\
\text { professional } \\
\text { development } \\
\text { Provide } \\
\text { pedagogical } \\
\text { support for tablets } \\
\text { Provide technical } \\
\text { support to teachers } \\
\text { and students } \\
\text { Develop tech } \\
\text { implementation } \\
\text { plan } \\
\text { Outreach to } \\
\text { community, } \\
\text { stakeholders } \\
\text { (including parents) }\end{array}$ & $\begin{array}{l}\text { School } \\
\text { administrators } \\
\text { Teachers } \\
\text { Students } \\
\text { Parents }\end{array}$ & $\begin{array}{l}\text { Tablets used in } \\
\text { pedagogically valuable } \\
\text { ways } \\
\text { Students engage with } \\
\text { tablets as learning and } \\
\text { productivity tools } \\
\text { Increased motivation } \\
\text { for learning } \\
\text { Equal access to } \\
\text { technology and related } \\
\text { resources } \\
\text { Become familiar with } \\
\text { tablets as tools of } \\
\text { engagement (not play } \\
\text { or media consumption) }\end{array}$ & $\begin{array}{l}\text { Funding to sustain and/or } \\
\text { expand program } \\
\text { Teachers get better at } \\
\text { using technology } \\
\text { Increased familiarity and } \\
\text { comfort with technology } \\
\text { Use for formative student } \\
\text { assessment } \\
\text { Teachers support each } \\
\text { other } \\
\text { Students get better at using } \\
\text { technology } \\
\text { Increased digital literacy } \\
\text { Learning how to use tablets } \\
\text { as productivity tools } \\
\text { Improved student learning } \\
\text { of content } \\
\text { Understand pedagogical } \\
\text { aspects of tablets }\end{array}$ & $\begin{array}{l}\text { Support for integrated } \\
\text { technology systems } \\
\text { Change in } \\
\text { instructional practice } \\
\text { Vetted toolbox of } \\
\text { pedagogically-sound } \\
\text { apps and other tools } \\
\text { that can enhance } \\
\text { learning } \\
\text { Digital citizens } \\
\text { System-wide } \\
\text { improved student } \\
\text { achievement }\end{array}$ \\
\hline
\end{tabular}

\section{ASSUMPTIONS}

1. Secure funding for effective continuation of efforts and program improvements

2. In-house knowledge (expertise) of technology and pedagogical uses

3. Technology, combined with effective instruction, can improve student outcomes 